\title{
Game Analysis on Safety Management of Construction Engineering
}

\author{
Ai-Hua LIU ${ }^{1, a}$, Wen-Bin XU ${ }^{1, b}$, Shi-Liang SHI ${ }^{2, c}$
}

${ }^{1}$ School of Environmental Science and Engineering, Guangdong University of Technology, Guangzhou, 510006, China

\author{
${ }^{2}$ School of Resource and Safe Engineering, Hunan University of Science and Technology, Xiangtan \\ 411201

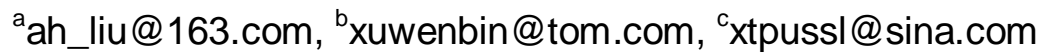

Keywords: Safety Management, Engineering Projects, Game Analysis, Policy.

\begin{abstract}
In view of the problem that the incidence of accidents in construction industry is high, and the safety management of construction enterprises is weak, the game theory was applied to study the safety management system of the construction engineering. The complete information static game and the incomplete information static game were used to analyze the problems existing in the process of policy implementation between the enterprises and the government. And the game between the enterprises and workers was analyzed through building the model, solving the model and analyzing the model. The causes was pointed out that the power of safety management of construction enterprises was deficiency, and that the income and cost Impacted on the result of games was showed. The suggestions on safety management of construction engineering were proposed from the angles of government and construction engineering enterprises, in order to strengthen and improve the safety management of the construction industry. The research results of this paper can provide realistic guiding significance for the supervision and management between government and the construction industry and the safety management of construction enterprise.
\end{abstract}

\section{Introduction}

At present our country is carrying out large-scale capital construction, but during the construction engineering, the safety management has always been ignored. It makes construction safety accidents occur frequently. It not only causes huge pecuniary loss, but also causes the casualties of plenty of people, then seriously influences the stability and development of society. The safe management of construction engineering project is the needs that the development of construction industry can be continued, healthy, and stabilized, is also important sustain that national politics is steady, society is stabilize, and people live and work in pleasure and content [1-2]. To guarantee to standardize and long-term for safety management of construction engineering, prevent the occurrence of the safety accidents of construction engineering, and raise the level of safety management, it is very necessary to establish the control system of safety. This paper carried out the game analysis from two aspects of government and enterprises, enterprises and staff, then found out the reasons that the power of safety management of construction enterprises is insufficient, then referred to some policy suggestions.

\section{The Game of Government and Enterprises}

The two major functions of safety management of construction engineering are to avoid and reduce the pecuniary loss of accidents, to defend management power, and guarantee the increment of socioeconomically wealth. Its realization mainly relies on the promote of external policy. Since the enforcement of safety measures of construction engineering need to consume plenty of capital and energy, these will increase the cost of enterprise management and will not bring direct profit, construction enterprises are forced to consider these problems mainly under the constraint of policy.

The execution course of construction engineering safety policy is essentially the process that the government transfers or imposes his value standard on enterprises, and the individual ration that enterprises pursues biggest profit often conflicts with the collective ration of pursuing social benefit[3-6]. If the policy is drawn up and enforced improperly, it is possible to cause that enterprises 
would rather select to pay for the penalty than adopt safety measures, even escape the responsibility of safety accidents. The local administrative department as actuator also has the benefit trend of himself, it is possible make the policy lose former purpose because of pursuing fine blindly. This is the game in the course that the government and enterprises implement policies [7-10].

\section{Game Models}

At present our country's safety management policy of construction engineering takes punishing as representative. Then make the course game between the government and enterprises in the penalty policy as the example, the analysis is as following. The main participants of the game are the government and enterprises, assuming two main parts rationally own maximization effectiveness. The government punishes enterprises whose safety measures are not in place or where projects safety accident happens through inspecting to guide that the enterprises comply with the safety rules and regulations of construction engineering and pay more attention to safety management. Two optional strategies of enterprises are to comply with or not to comply with. Two optional strategies of the government are to inspect or not to inspect. Assuming the cost is Ce that enterprises pay for complying with the safety rules and regulations of construction engineering, the profit is Re that it brings to the enterprises, the cost of government inspection is $\mathrm{Cg}$, the profit is $\mathrm{Rg}$ that it brings to the government, and the fines is $\mathrm{F}$ that the government gives enterprises for not complying with the safety rules and regulations of construction engineering. The payment game between enterprises and the government is shown in Table 1.

Tab. 1 the Payment Game between Enterprises and the Government

\begin{tabular}{|c|c|c|}
\hline $\begin{array}{c}\text { enterprise } \\
\text { government }\end{array}$ & to inspect & not to inspect \\
\hline to take measures & Re-Ce, $\mathrm{Rg}-\mathrm{Cg}$ & $\mathrm{Re}-\mathrm{Ce}, \mathrm{Rg}$ \\
\hline not to take measures & $-\mathrm{F}, \mathrm{F}-\mathrm{Cg}$ & 0,0 \\
\hline
\end{tabular}

\section{Game Analysis}

The Complete Information Static Game. Under this kind of condition, the government and enterprises take action at the same time, and know completely of the condition of each other (feature, payoff function and strategic space), from Table 1, That we can know this game has different balance states is as following:

(1) When Re-Ce $>0$, the safety measures of enterprises can gain profits, at this time the Nash equilibrium is "to take measures"and "not to inspect", this is also the most perfect result of this game, it is favorable for enterprises and society.

(2) When $-\mathrm{F}<\mathrm{Re}-\mathrm{Ce}<0$, the condition is fairly complex, if the government carries out "inspection", the optimum strategy of enterprises is "to take measures". If the government doesn't carry out "inspection", the optimum strategy of the enterprises is "not to take measures". Whether the government carries out "inspection" is relevant to the size of $\mathrm{Rg}, \mathrm{F}$ and $\mathrm{Cg}$.

(3) When $\mathrm{F}<\mathrm{Cg}$, the optimum strategy of the government is "not to inspect", at this time enterprises must select "not to take measures". When $\mathrm{F}>\mathrm{Cg}$, there is not Nash equilibrium.

(4) When $\mathrm{Re}-\mathrm{Ce}<-\mathrm{F}$, there are also two conditions: if $\mathrm{F}<\mathrm{Cg}$, the Nash equilibrium is "not to take measures", If $\mathrm{F}>\mathrm{Cg}$, the Nash equilibrium is "not to take measures" and "to inspect".

The Incomplete Information Satic Game. The foundation of above discussion is that enterprises and the government grasp the information of each other completely, but actual condition doesn' $t$ like this normally. In other words, enterprises don't know whether the government has ability to find out which enterprises comply with the safety rules and regulations of construction engineering and take safety management measures, and the cost of the inspection of government. Under this kind of condition, enterprises probably exist lucky psychology, and then carry out speculation.

From this the reasons that enterprises don' t comply with the safety rules and regulations of construction engineering and don' t take safety management measures can discover as following: 
(1)Take safety management measures doesn't have direct benefit for themselves, this is also the basic reason that enterprises are not willing to take safety management measures. Under the condition that enterprises are faced with survival problems, the urgent matter of enterprises is to develop management in order to get more economic profit. To take safety management measures cannot bring material economic benefit except increasing the cost. If the profit that enterprises obtain cannot be still remedied the cost which enterprises spend for taking safety management measures, enterprises come to a halt certainly.

(2)The punishment intensity is not enough, $\mathrm{F}$ is too low, it is the important reason that the punishment standard for occurring safety accidents also influences whether enterprises take safety management measures. If the fine $\mathrm{F}$ is lower, even below the net loss of taking safety management measures $(-\mathrm{F}<\mathrm{Re}-\mathrm{Ce}<0)$, enterprises would rather pay for the penalty than take safety management measures.

(3)The cost of government inspection is too high. Government inspection is a great threat for enterprises; it can force enterprises to take measures implementing safety control. But if the cost of government inspection is too high, making $\mathrm{F}-\mathrm{Cg}<0$, the government will not probably spend thought and financial resources in inspecting whether enterprises take safety management measures. If the government carries out inspection, it is possibly not worthwhile, the government has also own rational consideration. To guarantee that the effectiveness is biggest, the final equilibrium is "not to take measures" and "not to inspect", obviously this is the least positive state for society.

(4)Those enterprises take safety management measures is not large profit for government, local conducted departments may connive at no safety management of enterprises, and the policy lost meaning. Whether enterprises take safety management measures is relevant to the mandatory of the policy. And whether the government inspects is relevant to the profit of government. At present the direct profit for the government that enterprises take safety management measures is not large, more expression is a kind of social benefit. Under the condition of lacking of supervisor mechanism and social responsibility, fine income has possibly larger temptation for local conducted departments. This will cause the government to connive at no safety management of enterprises, and enterprises also reach the tacit agreement with the conducted departments, they would rather pay for fine, in order to avoid the larger expense because of taking safety management measures.

(5)The inspection ability of the government is a crucial factor which affects the behavior of enterprises. If enterprises believe that the government has enough technical strength to inspect accurately own safety management problems, the possibility that enterprises take safety management measures may be greatly raised. This factor has a little similar with the 3 th factor, that the ability of government is not enough means the threat of inspection is not to be trusted. Under this condition, the enthusiasm that enterprises take safety management measures also reduces greatly.

\section{The Game of Enterprises and Staff}

Basic Assumptions of the Model. (1) Players: there are three players in this game model: construction enterprises, staff and nature (fictitious player).

(2) Actions: assuming the action set which construction enterprises can select is: $M=\{M 1, M 2\}$ $=\{$ to command violating rules, not to command violating rules $\}$. The action set of staff is: $W=\{\mathrm{W} 1$, $\mathrm{W} 2\}=\{$ to implement, not to implement $\}$. The action set of nature is:: $\mathrm{N}=\{\mathrm{N} 1, \mathrm{~N} 2\}=\{$ to occur accident, not to occur accident $\}$.

(3) Information: The decisions of the players have certain order in this game model, the latter player takes action according to the decisions of the former, this game belongs to limited perfect information game.

(4) Action order and payoffs: If construction enterprises are "not to command violating rules", normally it will not occur accident, construction enterprises and staff get the returns that they have paid out normally, the payoffs are $(0,0)$. If engineering enterprises are "to command violating rules", and the staff are "not to implement ", then the staff are faced to reduce salary, be fired etc punishment $\mathrm{P}$ by construction enterprises, the mutual payoffs are $(0,-\mathrm{P})$. 
If construction enterprises are "to command violating rules", and the staff are "to implement". Assuming that the probability that nature occurs accident is $r$, there are two conditions: if not occurring accident, construction enterprises can get reward $\mathrm{G}$ for completing project in advance, staff can also get certain reward $b$, the mutual payoffs are $(G,-b)$; If occurring accident, construction enterprises will lose L, staff will be devastated or die, the loss is $\mathrm{H}$, the mutual payoffs are $(-\mathrm{L},-\mathrm{H})$.

This game tree of this game model is shown as Fig1.

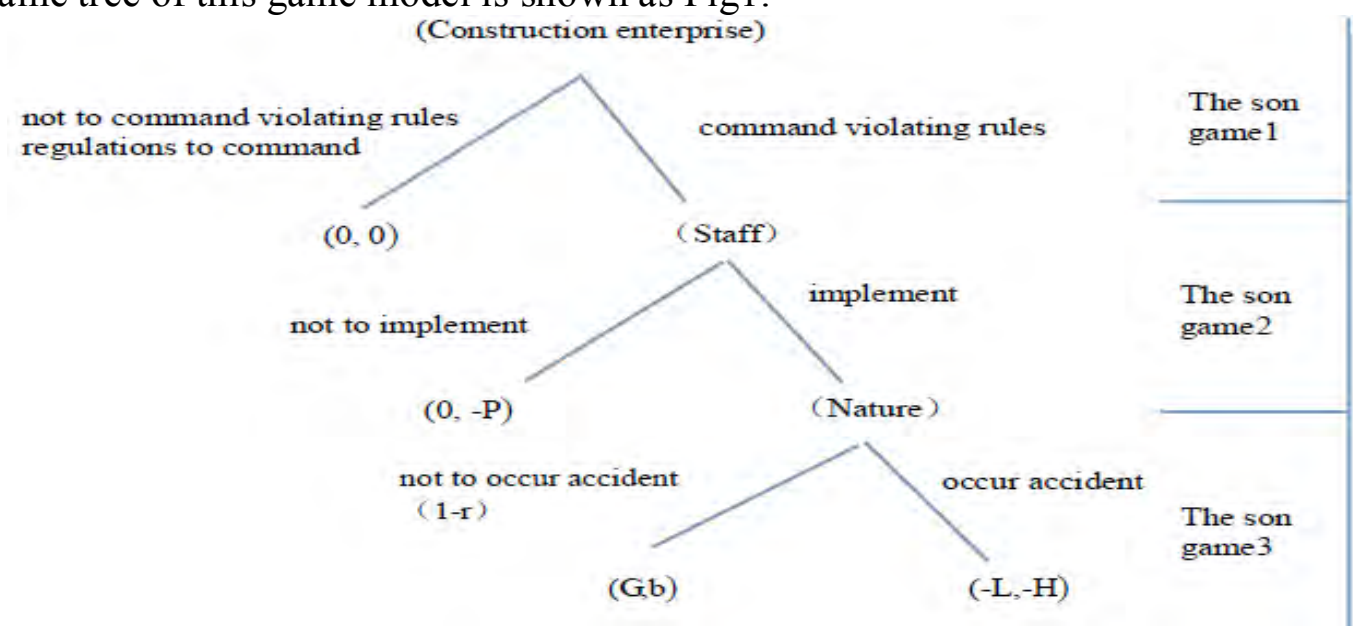

Fig. 1 The Game Tree of Engineering Enterprises and Staff

\section{The Solver of the Game Model}

The game model shown by Figl is a limited perfect information game. According to the theorem, a limited perfect information game has a pure strategic Nash equilibrium. Every decision knot of limited perfect information game is a individual information set, every decision knot begins a son game. Therefore, the concise Nash balance solver can be gotten by using the backward induction of dynamic planning.

(1)The option strategy of staff

In the son game3, the probability of nature occurring accident is $r$, the probability of nature not occurring accident is $(1-r)$. The profit expected value that construction enterprises get is $G(1-r)-\operatorname{Lr}$ $=\mathrm{G}-(\mathrm{G}+\mathrm{L})$, the profit expected value that the staff implement commander violating rules is $\mathrm{b}(1-\mathrm{r})$ - Hr. In the son game2, if the staff don't carry out commander, the expected profit is - P, assuming $\mathrm{P}=\mathrm{b}(1-\mathrm{r})-\mathrm{Hr}$, the effectiveness for the staff that the rewords the staff getting because of completing ahead of time produce is insignificant compared with the negative effectiveness that seriously wound or death brings, so $r=(b+p) /(b+H) \approx P / H$. Namely, when $r=P / H$, the staff select randomly to implement or not to implement. When $\mathrm{r}>\mathrm{P} / \mathrm{H}$, the staff select not to implement, the profit getting is $\mathrm{P}$. When $\mathrm{r}<\mathrm{P} / \mathrm{H}$, the staff select to implement, the profit getting is $(-\mathrm{Hr}>-\mathrm{P})$.

(2)The option strategy of construction enterprises

In the son game3, we can know from above analysis, the profit expected value that construction enterprises get is $\mathrm{G}-(\mathrm{G}+\mathrm{L}) \mathrm{r}$. In the son game2, under the condition that staff doesn't carry out the action, the profit of construction enterprises is 0 . Assuming $0=\mathrm{G}-(\mathrm{G}+\mathrm{L}) \mathrm{r}$, then $\mathrm{r}=\mathrm{G} /(\mathrm{G}+\mathrm{L})(7)$ : when $r=G /(G+L)$, construction enterprises select randomly to command violating rules or not to command violating rules. When $\mathrm{r}>\mathrm{G} /(\mathrm{G}+\mathrm{L})$, construction enterprises select not to command violating rules, the profit getting is 0 . When $r<G /(G+L)$, construction enterprises selects to command violating rules.

\section{The Analysis of the Game Model}

According to the characteristic of accident of our country construction enterprises and the present situation of construction enterprises management, we can know that usually $r \leq \mathrm{P} / \mathrm{H} \leq \mathrm{G} /(\mathrm{G}+\mathrm{L})$ can set up. From above analysis, it is known that the critical probability value of the option of construction enterprises is $(\mathrm{G} / \mathrm{G}+\mathrm{L})$. The critical probability value that staff can select is $\mathrm{P} / \mathrm{H}$, the probability that the accident occurs is $r$. Only make $r \geq G / G+L$ or $r \geq P / H$, then the accident can be avoided occur. 
(1)The size of the value of $\mathrm{P} / \mathrm{H}$ is decided by $\mathrm{P}$ and $\mathrm{H}$. For $\mathrm{H}, \mathrm{H}$ value of the risk favorite type staff is littler; $\mathrm{H}$ value of the risk detested type staff risk is bigger. $\mathrm{P}$ is that construction enterprises carry out the punishment for the staff not implementing commander and violating rules. So, in order to reinforce the training of staff safety consciousness and self value knowledge, to decrease reasonable punishment that construction enterprises adopts for staff can efficiently reduce the value $\mathrm{P} / \mathrm{H}$, then reduce the probability that the staff implement commander violating rules.

(2)The the size of value G/ ( G+ L) is decided by reward G for completing in advance and accident punishment $\mathrm{L}$, so to reduce award intensity, to increase accident punishment intensity, and to change reward for completing in advance into safe award etc measures can reduce the value $G /(\mathrm{G}+\mathrm{L}$ ) efficiently, then reduce the probability that construction enterprises command violating rules.

\section{Summary}

Though above analysis on the game of construction engineering safety, some summaries and suggestions are given as following:

(1)Rigorously control the safe management standard, strengthen the punishment intensity. The safety management system is the effective guarantee to raise the level of construction engineering safety management and decrease the safety accidents of construction engineering. The key that the system can produce effectiveness lies in the choice of controlling standard of construction engineering safety management. If the standard is too low, the penalty amount cannot take effect of warning and punishing construction enterprises, so enterprises would rather select to pay for the penalty than take actively construction engineering safety measures, then the hidden dangers cannot be cut off from fountainhead. If the standard is too high to exceed the technical ability, it can also make enterprises lose the enthusiasm of technical innovation and enterprises are not willing to put fund into safety management. Therefore, the control standard of construction engineering safety management should not only accord with the realization ability of enterprises, but also satisfy the bearing ability of society for the safety accidents of construction engineering.

(2)Improve the ability of the government's monitoring and credibility. Enterprises and the government are two behavior main parts in the course that the safety management measures of construction engineering are taken into effect. Since the benefit trend of each is different, there is the contradiction between them. The safety management of construction engineering is mainly the result of the game of them. On one hand the government controls and forces enterprises to take safety management measures of construction engineering through the policies, On the other hand, enterprises will rationally "escape" responsibility for the pursuit to the profit. If the government has enough technological ability to finish the inspection with lower cost, or the government adopts "promising action", and lets enterprises believe firmly that the government will be sure to take action to inspect the safety situation of construction engineering, then enterprises will take technological means voluntarily to improve the negative effects so as to avoid suffering greater losses for being punished.

(3)Improve management system to prevent the policy conducted department from conniving at enterprises not reaching safety standard for one's own interests. The administrative department has also own interest consideration. When the safety management of construction enterprises can't bring benefit for it, the administrative department probably connives at the enterprise not reaching safety standard in order to pursue the fine; this just makes the policy lose the meaning. So, on the one hand, it is necessary to improve management system, and then to assess working achievement of the administrative department will consider the situation that the administrative department implements the safety management and supervision for construction enterprises. On the other hand, it is necessary to set up re-supervisory system of the policy conducted department and standardize strictly the work of the policy conducted department.

(4)Raise the knowledge on the safety management of construction engineering; strengthen the safety management of construction engineering. The ideal state of strengthening the safety management of construction engineering and taking safety control measures should be the "both gaining" for government and enterprises, namely with the improvement of the level of the safety management of 
construction engineering, the economic benefit of construction enterprises and the social benefit of construction engineering safety both increase notably. The foundation of modern safety management is to know safety management correctly; it is wrong idea that to strengthen safety management of construction engineering will increase invests of enterprises. Through various propaganda and education forms the atmosphere of "Everybody notices safety for everything at any time", and realizes the thoughtful stride across "need me to notice safety" to "I want to notice safety" step by step, further reach the realm of "I know safety". To prevent is main, to administer

(5)Should be in advance, then safety measures are ensured to be in place. Staff is directly conductor of the safety management of construction engineering, is also the direct victim after accidents occur. To raise the level of the safety management of construction engineering needs participate of staff. First, the staff should be given the corresponding supervisor power of safety management, and the emergence of the incident of getting reprisal because of reporting violation should be prevented. Secondly, strengthen the safety education and training for the staff to raise the quality of the staff. In addition, the supervision for construction enterprises can improve through the media participating etc.

\section{Acknowledgement}

This research was financially supported by the National Science Foundation of China (No $51274100)$.

\section{References}

[1]LI Mei-ling. The Research of Construction Enterprise Safety Management Based on Game Theory [D]. Shenyang: Shenyang Jianzhu University, 2011.

[2]Hinze J W. Incurring the costs of injuries versus inversing in safety[A] In: Coble R Hinze J and Haupt T C, eds. Construction Safety and Health Management[M].New Jersey: Prentice Ha11, 2000(7).

[3]ZHANG Wei-ying. Game Theory and Information Economics (10th edition) [M]. Shanghai: Shanghai people's publishing house, 2004.

[4]LUO Yun. Safety Economics of Construction Engineering [M]. Beijing: chemical industry press, 2004.

[5]JIN Long-zhe, SONG Cun-yi . Safety Science Principle of Construction Engineering [M]. Beijing: chemical industry press, 2004.

[6]GUO Hai-yang. Research on construction safety Management of Construction based on Game Theory [D]. Shijiazhuan: Shijiazhuan Tiedao University, 2014.

[7]REN Guo-qiang, ZHANG Hong-yan. Research of Game theory Applying to Construction Engineering Management [J]. Journal of Tianjin University of Technology, 2002, 25 (1):88-90.

[8]CHENG Yi. Application of Game Theory in Quality Inspection of Construction Engineering[J]. Journal of Chongqing Jianzhu University, 2002, 24 (6):77-79.

[9]REN Zhi-wen. The construction safety government regulators Game Analysis and Path Selection [D]. Jinan: Shandong Jianzhu University, 2013.

[10]YANG Gao-sheng, LI Jie, WANG Lu, et al. The Ethics Game Analysis of Government Regulation and safety management of construction enterprise [J]. Construction Economy, 2011, 32(10):87-90. 